\title{
Assessment of Soil Fertility under Northern Light Soil Area of FCV tobacco in Andhra Pradesh
}

\author{
L K PRASAD ${ }^{1 *}$, J POORNA BINDU ${ }^{2}$, D DAMODAR REDDY ${ }^{3}$, CHANDRASEKHARA RAO ${ }^{1}$ AND H RAVISANKAR ${ }^{1}$
}

\section{ABSTRACT}

An assessment of soil fertility of Northern Light Soil area of FCV tobacco was carried out to study the status of soil macro and micronutrients. Soils of the study area are mostly moderately acidic in nature with low organic carbon and available nitrogen with a mean value of $0.29 \%$ \& $110 \mathrm{~kg} \mathrm{ha}^{-1}$, respectively. Available phosphorus was high (88\% samples) with a mean value of $92.6 \mathrm{~kg} \mathrm{ha}^{-1}$. While the average available potassium content was $297 \mathrm{~kg} \mathrm{ha}^{-1}$ with $48 \%$ samples in medium class. Among available micronutrients, the available zinc content in 73 $\%$ of samples was very low - low ( 0.0 to $0.6 \mathrm{ppm})$. Whereas the availability of copper in 25 $\%$ samples was very low to low as per the fertility class $(0.0-0.30 \mathrm{ppm})$. Available iron (18.8 $-35.03 \mathrm{ppm}$ ) and manganese (17.03-21.5 ppm) contents were high in the region. Nutrient index of available nitrogen was 1.00 (Low) while, NI was 2.83 (High) \& 2.36 (Medium) for available phosphorus and available potassium, respectively.
\end{abstract}

KEYWORDS

Soil fertility, Soil micronutrients, Nutrient index, FCV Tobacco

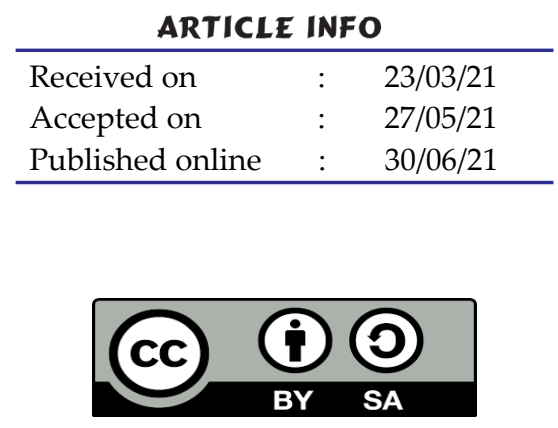

\section{INTRODUCTION}

A ssessment of Soil fertility including micronutrients in areas growing commercial crops is important to manage natural resources, crop diversification and enhancing production levels. Soil plays a major role in determining the sustainable productivity of an agro ecosystem. The sustainable productivity of a soil depends upon its ability to supply essential nutrients to the crop. Macro and micronutrients levels in soils are reducing due to continuous mining of nutrients without replenishment. It is well known that optimum plant growth and crop yields depend upon plant available nutrients in soil to the crop not on their total concentration (Singh et al (2013)).

FCV (Flue cured Virginia) tobacco's leaf quality is important commercially. Nitrogen and potassium play a key role in improving the quality of leaf. Efficient use and management of nitrogen and potassium nutrients is essential for tobacco crop growth and quality. Similarly, application of micronutrients is very important for getting high yield and quality of tobacco. Maximum percentage of top-quality leaves was obtained with application of higher dose of $\mathrm{Cu}$ fertilization (Hoppe, 1988). Baber and Haq (1987) mentioned that $\mathrm{Zn}$ and B application increased the yield of FCV tobacco, while $\mathrm{Cu}$ fertilization increased the potash and sugar contents of tobacco.

In this context the study is relevant in assessing the status of soil fertility including macro and micronutrients in Northern light textured soils of Andhra Pradesh in which FCV tobacco is being cultivated as most remunerative commercial crop.

\section{MATERIALS AND METHODS}

Study area under FCV tobacco (Northern Light Soils)

The study area in NLS (a production zone under FCV tobacco) is a part of West Godavari district (Geographical area of 7075 sq.km) of Andhra Pradesh. NLS produces export quality of FCV tobacco which is one of the major production zones of FCV tobacco in India. Normal Annual rainfall is $1078 \mathrm{~mm}$. Major physiographic units are alluvial plains and uplands. Predominant geological formations are Alluvium, Tertiaries, Gondwanas, Deccan traps and Archeans.

Natural resources and crops in NLS

The study area is a conglomerate of red sandy loams to sandy clay loams in uplands and Clay loams to clay in deltaic alluvial plains. The soils in the area come under the soil taxonomic classes are Rhodustalf, Ustochrept and Haplusterts formed from red sandstones, crystalline metamorphic rocks and Alluvium parent materials. The major crops grown in the area besides irrigated FCV tobacco are Oil Palm, Maize, Sugarcane, Cotton, Chilies, Groundnut and Paddy. Predominate orchard crops are Mango, Cashew and Coconut. Aliveru, Jalleru, Yerrakaluva and Polavaram left canal are the major irrigation source besides borewells and local ponds.

Sample collection and Analysis

Soil sampling was done in FCV tobacco growing villages of the northern light soil area of West Godavari district under five auction platforms of Tobacco board, Government of India. Representative FCV tobacco growing villages were selected to achieve better spatial distribution so as to capture the heterogeneity in the sampling with respect to soil types,

\footnotetext{
1 Principal Scientist, Central Tobacco Research Institute, Andhra Pradesh - 533 105, Rajahmundry, India

2 Scientist, Central Tobacco Research Institute, Andhra Pradesh - 533 105, Rajahmundry, India

3 Director, Central Tobacco Research Institute, Andhra, Pradesh - 533 105, Rajahmundry, India

*Corresponding author email: lkprasad123@gmail.com
} 
Table 1: Soil fertility status of FCV tobacco soils under NLS region of Andhra Pradesh (Mean values)

\begin{tabular}{|c|c|c|c|c|c|c|c|c|}
\hline $\begin{array}{l}\text { Auction Plat- } \\
\text { form areas }\end{array}$ & $\begin{array}{l}\text { Organic } \\
\text { car- } \\
\text { bon } \\
(\%)\end{array}$ & $\begin{array}{l}\text { Available } \\
\text { Nitrogen } \\
\text { (kg/ha) }\end{array}$ & $\begin{array}{l}\text { Available } \\
\text { Phospho- } \\
\text { rous } \\
(\mathrm{kg} / \mathrm{ha})\end{array}$ & $\begin{array}{l}\text { Available } \\
\text { Potassium (kg/ha) }\end{array}$ & $\begin{array}{l}\text { Available } \\
\text { Copper } \\
(\mathrm{ppm})\end{array}$ & $\begin{array}{l}\text { Available } \\
\text { Zinc } \\
(\mathrm{ppm})\end{array}$ & $\begin{array}{l}\text { Available } \\
\text { Iron } \\
(\mathrm{ppm})\end{array}$ & $\begin{array}{l}\text { Available } \\
\text { Manganese } \\
(\mathrm{ppm})\end{array}$ \\
\hline Devarapalli & 0.24 & 119.8 & 87.1 & 301.0 & 1.29 & 0.74 & 18.8 & 20.7 \\
\hline Gopalapuram & 0.31 & 118.3 & 113.8 & 344.0 & 0.74 & 1.07 & 25.6 & 19.6 \\
\hline Koyyalagudem & 0.32 & 118.6 & 88.2 & 330.6 & 1.17 & 0.89 & 35.03 & 21.2 \\
\hline $\begin{array}{l}\text { Jangared } \\
\text { dygudem - II }\end{array}$ & 0.26 & 94.3 & 95.8 & 207.7 & 0.64 & 0.85 & 24.4 & 17.03 \\
\hline $\begin{array}{l}\text { Jangared } \\
\text { dygudem - I }\end{array}$ & 0.31 & 98.8 & 78.3 & 305.6 & 0.72 & 1.04 & 31.97 & 21.5 \\
\hline
\end{tabular}

land use and crops. Surface soil samples of 0-15 $\mathrm{cm}$ depth were collected from 116 villages across five auction platforms. Soil samples were shade dried and the processed samples $(<$ $2 \mathrm{~mm}$ sieved) were used for physico-chemical and chemical analysis to determine soil fertility with the help of standard procedures (Jackson (1967) ). The important soil parameters i.e $\mathrm{pH}$, electrical conductivity, organic carbon, available major nutrients (N, P \& K) and available micronutrients were analysed for their status. Analysis of $\mathrm{Zn}, \mathrm{Fe}, \mathrm{Mn}$ and $\mathrm{Cu}$ was performed using Diethylene Tri-amine Penta Acetic acid (DTPA) extract and with the help of AAS as outlined by Lindsay and Norvell (1978) . The nutrient index (NI) values for available micronutrients nutrients present in the soils were calculated utilizing the formula as suggested by Parker et al (1951) and classified this index as low (<1.5), medium (1.5 to 2.5) and high $(>2.5)$. It was calculated as under.

Nutrient index $=(\mathrm{Nl} \times 1)(\mathrm{Nm} \times 2)(\mathrm{Nh} \times 3) / \mathrm{Nt}$

Where, $\mathrm{Nl}, \mathrm{Nm}$ and $\mathrm{Nh}$ are the number of soil samples falling in low, medium and high categories for nutrient status and are given weights of 1,2 and 3 , respectively. $\mathrm{Nt}$ is the total number of samples.

\section{RESULTS AND DISCUSSION}

\section{Soil fertility status}

The $\mathrm{pH}$ values obtained from the analysis of the soil samples indicated that the northern light soils are mostly moderately acidic in nature and few samples are strongly acidic nature. The $\mathrm{pH}$ values ranged from 4.36 to 8.87 . The mean value was 6.43. In only some patches the soils are near neutral to slightly alkaline in nature. The electrical conductivity values showed that the soils are free of salts. The EC values ranged from 0.01 to $0.6 \mathrm{dS} / \mathrm{m}$. Soils are well within the salt free limits. The mean available of organic carbon content of NLS was 0.29 per cent, while it varied from 0.24 to $0.31 \%$ among the auction platform areas. The mean available nitrogen content was 110.0 $\mathrm{kg} / \mathrm{ha}$ and it varied from 94.3 to $119.8 \mathrm{~kg} / \mathrm{ha}$ between different auction platform areas (Table 1 \& Figure 1 ).

The area soils are classified under low soil fertility class. Whereas available phosphorus content in the region was high. The mean value was $92.6 \mathrm{~kg} / \mathrm{ha}$. High amounts of $\mathrm{P}$ accumulation was happened due to excess addition of $\mathrm{P}$ fertilizer during the cultivation of the crop by the farmers.

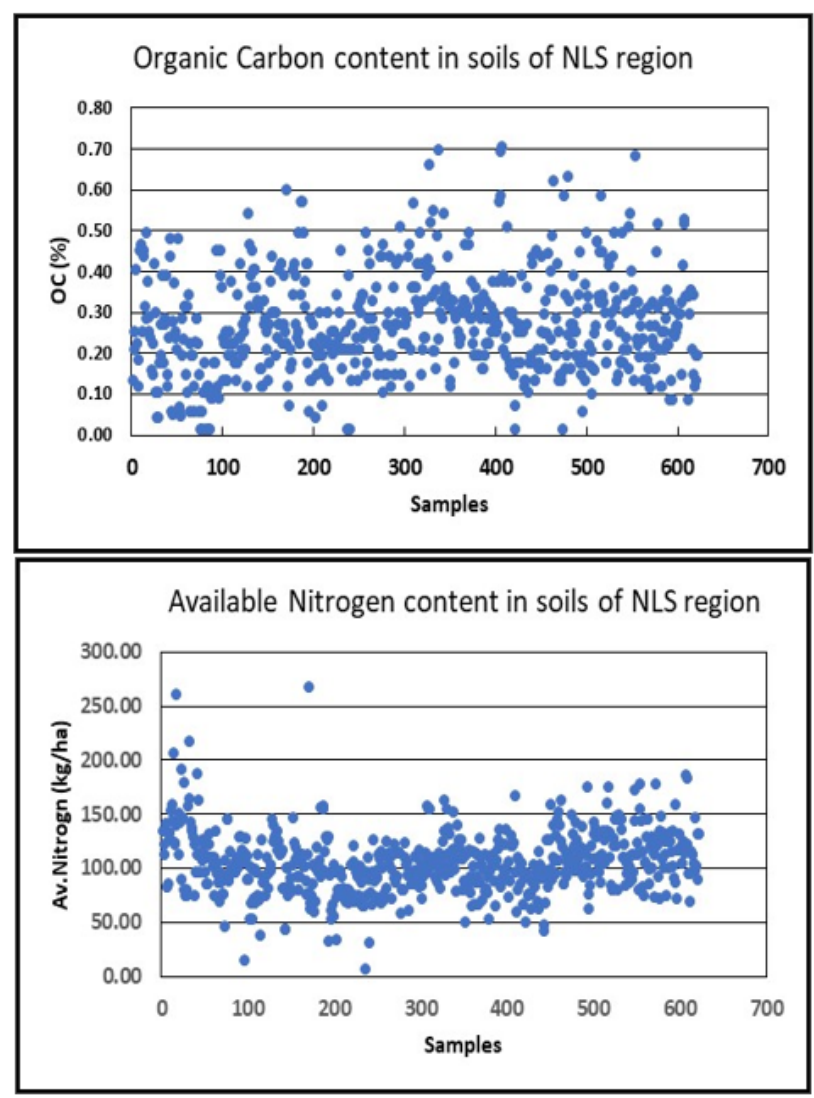

Fig. 1: Status of soil organic carbon and availablenitrogen in NLS region

In addition, the uptake of phosphorus by FCV tobacco crop is low i.e. $6-8 \mathrm{~kg} / \mathrm{ha}$. The study indicated that available phosphorus content in $88 \%$ of the samples are in the high fertility class (> $20 \mathrm{~kg} / \mathrm{ha}$ of $\mathrm{P}$ ) and remaining $12 \%$ samples are in lowmedium range (Figure 2 ). The mean available potassium content varied from 208.0-344.0 kg/ha among auction platforms. The mean available potassium content was $297 \mathrm{~kg} / \mathrm{ha}$. The 
Table 2: Nutrient indices ofFCV tobacco soils under NLS region of Andhra Pradesh

\begin{tabular}{|c|c|c|c|c|c|c|}
\hline \multirow{2}{*}{$\begin{array}{l}\text { Fertility } \\
\text { Parameter }\end{array}$} & \multicolumn{5}{|c|}{ Nutrient index (NI) } & \multirow{2}{*}{$\begin{array}{l}\text { Mean of } \\
\text { NLS region }\end{array}$} \\
\hline & Janga reddy gudem-II & Janga reddy gudem-I & Koyyala gudem & Gopala puram & Devara palli & \\
\hline Organic carbon & 1.01 & 1.06 & 1.17 & 1.14 & 1.01 & 1.07 \\
\hline Nitrogen & 1.00 & 1.00 & 1.00 & 1.00 & 1.00 & 1.00 \\
\hline Phosphorus & 2.83 & 2.78 & 2.81 & 2.95 & 2.81 & 2.83 \\
\hline Potassium & 2.07 & 2.49 & 2.55 & 2.54 & 2.41 & 2.36 \\
\hline Copper & 2.01 & 2.05 & 2.32 & 2.05 & 2.32 & 2.11 \\
\hline Zinc & 1.25 & 1.37 & 1.24 & 1.43 & 1.19 & 1.29 \\
\hline Iron & 2.92 & 2.95 & 2.98 & 2.96 & 2.80 & 2.93 \\
\hline Manganese & 2.99 & 2.99 & 3.00 & 3.00 & 3.00 & 2.99 \\
\hline
\end{tabular}

Low: <1.5 Medium: 1.5-2.5 High: >2.5 (Parker et al, 1951)

percentage distribution of available $\mathrm{K}$ status showed that $9 \%$ samples are in low, $48 \%$ samples are in medium and $43 \%$ are in high status (Figure 2).

The samples were analysed for available micronutrients for their status. The available zinc in the soils of NLS region ranged from 0.03 to $9.57 \mathrm{ppm}$ while mean values in different auction platforms ranged from 0.74 to $1.07 \mathrm{ppm}$ (Table 1) within NLS region. About $22 \%$ samples are very low in available zinc and $51 \%$ samples are in low class.

In case of available copper content, $25 \%$ samples are in very low to low class ( $0.0-0.30 \mathrm{ppm}), 37 \%$ samples are in medium class and remaining is in high class (Figure 3). Micronutrient deficiencies were found in soils of Andhra Pradesh, Telangana and Karnataka, (Prasad et al (2016) and Prasad et al (2017) ) especially available forms of zinc and iron.

The available iron content in the samples analysed varied from 02.13 to 94.04 ppm with mean values of 18.8 to 35.03 ppm between auction platform areas and most of the samples were in high to very high range. Only $5 \%$ samples were under low to medium class. The available manganese content in the samples ranged from 3.34 to 56.3 ppm with mean content of 17.03 to $21.5 \mathrm{ppm}$ among the auction platform areas and most of the samples are in very high range. Acidic $\mathrm{pH}$ conditions and Fe and Mn containing parent material of the soils led to higher availability of these two micronutrients.

\section{Nutrient indexes}

Organic Carbon: Nutrient index of organic carbon in NLS is 1.07and the fertility status is classified as Low. Among different auction platforms, lowest value (1.01) was observed in soils under Jangareddygudem -II and Devarapall (Table 2).

Available Nitrogen: Nutrient index of available nitrogen in NLS is 1.00 and the fertility status is low. Among all the villages the nutrient index of nitrogen is same.

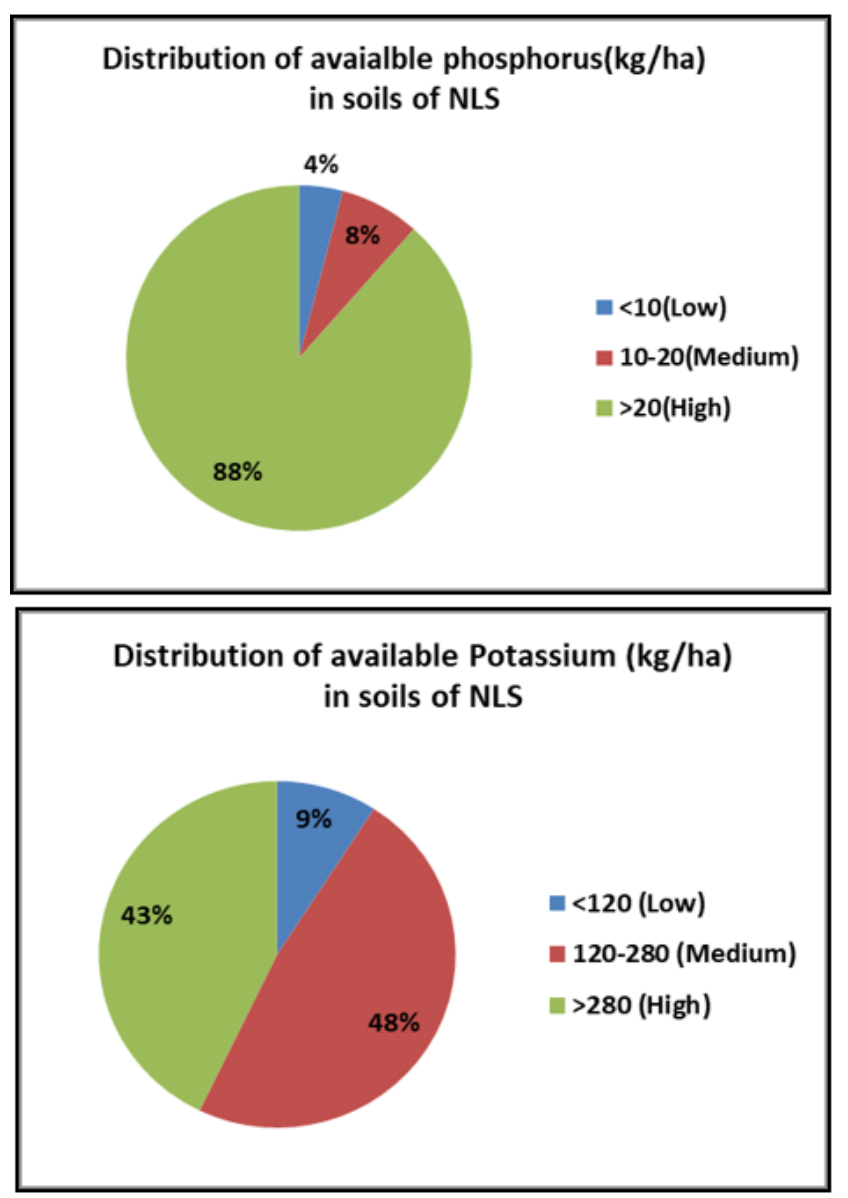

Fig. 2: Status of soil available phosphorus andavailable potassium in NLS region

Available Phosphorus: Nutrient index of available phosphorus in NLS is 2.83 and the fertility status was high. The highest index value (2.95) of phosphours was observed in Gopalapuram auction platform area. 


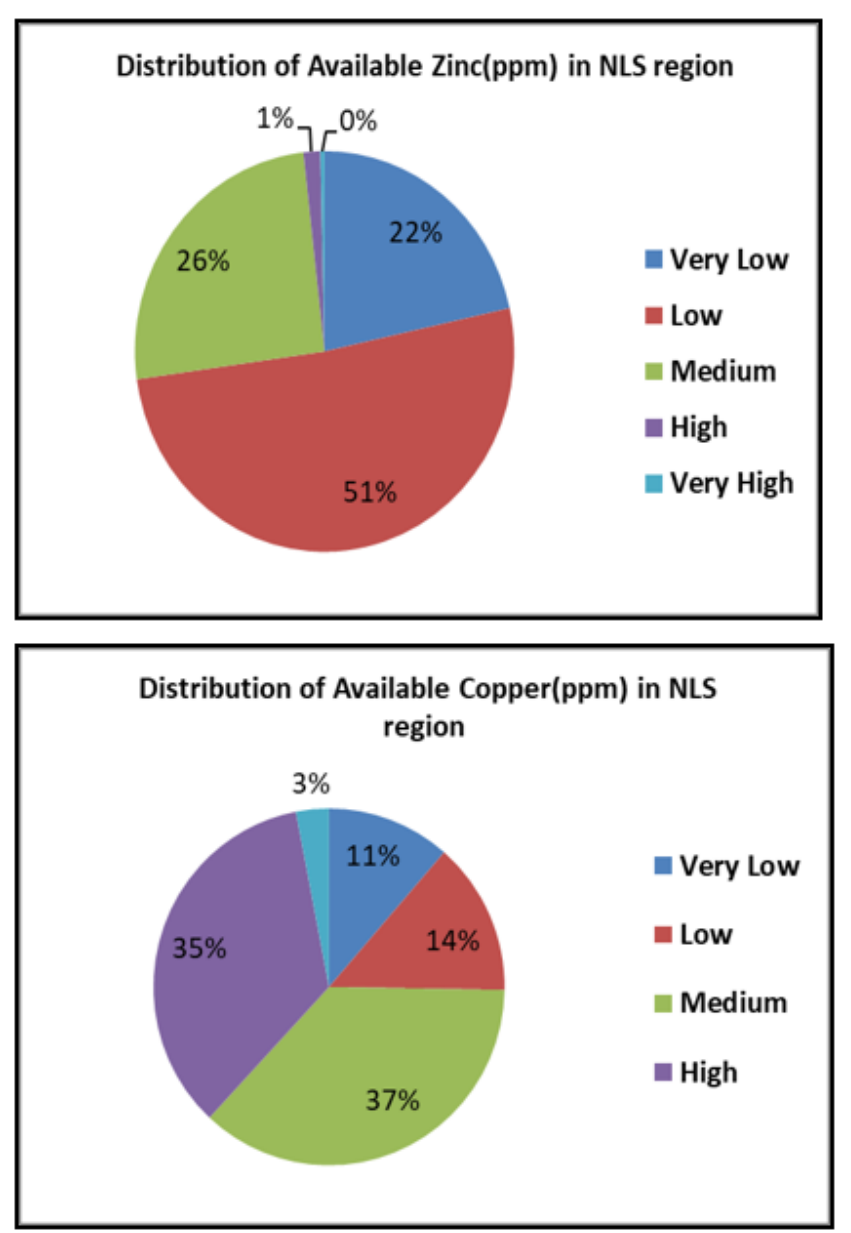

Fig. 3: Distribution of available zinc and copper statusin soils of NLS region

Available Potassium: Nutrient index of potassium in NLS is 2.36 and it was categorized under medium fertility class. Whereas the fertility status of $\mathrm{K}$ in Koyyalagudem and Gopalapuram areas are categorized as high (2.54 -2.55).

Available Copper\& available zinc: Nutrient index of Copper in NLS is 2.11 and it was categorized as medium. Among the auction platforms, highest value was observed in Koyyalagudem (2.32). Nutrient index of Zinc in NLS is 1.29 and it was categorized under fertility class of low. Among soils under the auction platforms, lowest observed under in Devarapalli (1.19) whereas highest index value observed under Gopalapuram (1.43).

Available Iron \& available Manganese: Nutrient index of Iron in NLS is 2.93 and the fertility was categorized as high. Among the soils under auction platforms, the nutrient index values for Iron ranged from 2.80 to 2.98 and the fertility status was high. Nutrient index of Manganese in NLS is 2.99 and it was categorized as high. Among the auction platforms the nutrient index values ranged from 2.99-3.00 for Mn (Table 2).

\section{CONCLUSION}

The study of assessment of soil fertility of Northern Light Soil area of FCV tobacco indicated that the soils are low in both organic carbon and available nitrogen content with high available phosphorus content. Whereas available potassium was medium to high in these soils. Among available micronutrients, available zinc in $73 \%$ samples were very low to low followed by available copper where $25 \%$ samples are in very low to low class. Therefore, it is concluded that these soils need improvement in organic carbon content of soils and available nitrogen content. Recommended practices of organic manures and in-situ green manuring would improve the soils. Addition of phosphorus fertiliser is to be regulated to reduce the accumulation of phosphorus in the soils and addition of recommended dose of zinc fertilisers will increase the availability of zinc for the crop wherever it is low or deficient.

\section{ACKNOWLEDGEMENT}

The authors profoundly acknowledge the financial and field level support given by Tobacco Board, Govt. of India through their sponsored project.

\section{REFERENCES}

Baber SA and Haq L 1987. The yield and quality of flue-cured Virginia tobacco as affected by the application of micronutrients. In Proceedings of the national seminar on micronutrients in soils and crops, 191-195.

Hoppe BR. 1988. Effect of different rates of copper on flue-cured tobacco. Proceedings of 9th International 126-127.

Jackson ML. 1967. Soil Chemical Analysis. Pvt. Ltd. New Delhi 42-48.

Lindsay WL and Norvell WA. 1978. Development of a DTPA Soil Test for Zinc, Iron, Manganese, and Copper. Soil Science Society of America Journal 42(3):421-428. url: https://dx.doi. org/10.2136/sssaj1978.03615995004200030009x. doi: 10.2136/ sssaj1978.03615995004200030009x

Parker FW, Nelson WL, Winters E and Miles IE. 1951. The Broad Interpretation and Application of Soil Test Information. Agronomy Journal 43(3):105-112. url: https://dx.doi. org/10.2134/agronj1951.00021962004300030001x. doi: 10.2134/ agronj1951.00021962004300030001x

Prasad LK, Damodar RD, Chandrasekhararao C, Bj P and N J. 2016. Assessment of soil micronutrient status of southern light soils under Flue Cured Virginia tobacco in Prakasam district of Andhra Pradesh. International Journal of Tropical Agriculture 34(7):2397-2401.

Prasad LK, Reddy D, Chandrasekhararao D, C, Bindu P and N J. 2017. Assessment of soil micronutrient status of Karnataka light soils under Flue Cured Virginia tobacco in Mysore district of Andhra Pradesh. Tobacco Research 43(1):38-42.

Singh AK, Singh KA, Bharati RC and Chandra N. 2013. Response of intercrops and nutrient management on the performance of tobacco based intercropping system and assessment of system sustainability. Bangladesh Journal of Botany 42(2):343-348. url: https://dx.doi.org/10.3329/bjb.v42i2.18040. doi: 10.3329/ bjb.v42i2.18040 